enough for discharge from psychiatric inpatient care. It would facilitate nurse training, teaching of undergraduate medical students and other health professionals as well as providing a more homely atmosphere for patients than that of the district general hospital.

It appears that on closure of a large psychiatric hospital, one should provide for the most dependent patients first and create around them a mental health service uniting its various practitioners, other medical specialists, and the primary care service with other caring professionals and voluntary organisations. Clearly relationships with voluntary organisations and Social Services Departments need to be developed to ensure continuing access of patients of a kind previously resident in the large psychiatric hospital for long-term care. Facilities for those patients will now be funded from the rundown of the large hospital and supplementation from the Department of Health and Social Security. Access to such facilities must continue to enable the minimal non-acute provision and the acute provision, including that for the functionally ill elderly psychiatric patient of 0.44 per thousand, to operate efficiently.

A district mental health service to provide service requirements, to plan, budget and manage, to provide monitoring and facilitate training, teaching of undergraduates and postgraduates and research, would best function if the component of the health service, social services and voluntary organisations were operating as a single unit. This may have to be accomplished at an operational rather than an administrative level. Both Working Parties and Management Committees of services funded from the rundown of the psychiatric hospital and new joint ventures should have on them the Community Physician responsible for mental health liaison, Social Services mental health executive, Community Health Council secretary, representatives of voluntary organisations, a district health authority member, a city councillor and medical, nursing and other professional representatives of those operating the mental health service, particularly the Consultant Psychiatrist responsible for rehabilitation and the Psychiatric Nursing Officer responsible for residential and community psychiatric nursing services.

Research into evaluation of neuroleptic treatment in chronic schizophrenia, social deprivation in the inner city and consequences for mental health services, and evaluation of an eight-bedded unit for high dependency patients who might be discharged from the care of the psychiatrists, but continue on an outpatient basis with psychology, social work and psychiatric nursing in a residential setting, is clearly relevant to our planning in Liverpool at present.

The Royal College of Psychiatrists North-West Division had a meeting on Hospital Closure at Rainhill Hospital on 15 January 1986 and a further Rehabilitation Symposium took place on 7 March 1986 reviewing progress in the region, concentrating on the retraining and redeployment of psychiatric nursing staff.

No development as outlined above can be cheaper than the large psychiatric hospital and it is with some excitement we may look forward to beneficial change for our future patients and ourselves.

\section{ACKNOWLEDGEMENTS}

I am grateful to Dr David Enoch, Professor John Copeland, Dr Julian Leff and Dr John Howat for their time, interest and encouragement.

\title{
Diploma in Geriatric Medicine
}

In December 1985 the first examination was held for the Diploma in Geriatric Medicine. This examination is not intended for those aiming to be consultants in geriatric medicine but is intended for doctors wishing to contribute to the geriatric services of their district in a non-consultant capacity, in particular general practitioners wishing to do sessions as clinical assistants or hospital practitioners.

Psychiatric trainees who have spent a rotating placement in a psycho-geriatric unit might well wish to consider applying for the exam. A number of psycho-geriatricians are members of the Board of Examiners.

General practice trainees may find it convenient to take the Diploma during their vocational training (as for the
Diploma in Child Health). Entry qualifications include a period of experience in a hospital department providing specialist geriatric or psychogeriatric services.

The examination comprises both written and clinical sections and its emphasis is on the practicalities of patient management, particularly in community and primary care settings.

Doctors interested in taking the Diploma can obtain copies of the regulations, syllabus, specimen questions and suggested reading material from the Royal College of Physicians, 11 St Andrew's Place, Regent's Park, London NW1 4LE. 